\title{
The influence of mother-infant skin-to-skin contact on bonding and touch
}

\author{
*Karen Louise Potgieter, BSc OT (UCT), MSc OT (Wits) https://orcid.org/0000-0003-4 I I 9-966 I \\ Private Practitioner \\ Fasloen Adams, B OT (US), MSc OT (UCT), PhD (WITS) https://orcid.org/0000-000 I-6742-3727 \\ Head, Department of Occupational Therapy, School of Therapeutic Sciences, Faculty of Health Sciences, University of the \\ Witwatersrand
}

Introduction: Early skin-to-skin contact is a biological need of new born infants. Preliminary research informs us that this contact directly and indirectly influences the mother-infant relationship. This relationship in turn forms the basis of the infant's social-emotional development. This study investigated South African mother-infant dyads with varying exposure to early skin-to-skin contact and the influence on bonding and touch within the mother-infant relationship.

Method: Contact over the first 24 hours and bonding were measured within one week postpartum. At six to eight weeks postpartum, the bonding assessment was repeated together with objective analysis of mother-infant touch during face-to-face interaction and mothers' self-reported use of affectionate touch in daily routine.

Findings: No correlation was found between a longer duration of skin-to-skin contact and bonding within one week postpartum. A positive correlation was identified between two hours or more of skin-to-skin contact and bonding as well as a higher rating of affectionate touch during feeding at six to eight weeks postpartum. This was substantiated by an increase in touch during face-to-face interaction.

Conclusions: Early skin-to-skin contact positively influences mother-infant bonding and touch at six to eight weeks postpartum. Further more stringent research is however required to confirm these findings.

Key words: Skin-to-skin contact, mother-infant relationship, bonding, maternal-infant touch, breastfeeding, affectionate touch, social emotional development

\section{INTRODUCTION}

Skin-to-skin contact refers to the contact between an infant and an adult when the infant is placed in a prone position (naked or wearing only a diaper) onto the mother's bare chest' .

Skin-to-skin contact was initially used as an alternative means of care for preterm infants in hospital settings where technology and resources were lacking. This form of care resulted in better outcomes for these premature infants and the mother-infant dyad as a whole. These outcomes included a positive effect on infants' physiological, immunological and later motor and cognitive developmental outcomes ${ }^{2-4}$. This could be partly attributed to improved breastfeeding outcomes for the dyad ${ }^{5}$. Skin-to-skin contact also had a positive influence on bonding and attachment between the dyad $^{2}$. Taking into account the improved outcomes, skin-to-skin contact was recommended globally for use as an intervention for this vulnerable population of preterm infants.

Skin-to-skin contact was later promoted as one of the 10 steps to successful breastfeeding in the Baby Friendly Hospital Initiative $(\mathrm{BFHI})^{6}$. This initiative encourages practices that promote and support breastfeeding which in turn can help reduce the rates of infant morbidity and mortality ${ }^{7}$. The BFHI is especially relevant in South Africa, where the infant mortality rates remain unacceptably high, as highlighted in the 20II Tshwane declaration in support of breastfeeding ${ }^{8}$. One of the key components of the initiative is the recommendation that infants be placed and remain in immediate skin-to-skin contact on their mother's chest directly after birth until the first breastfeed or for at least two hours after birth ${ }^{7,9}$. This two hour period after birth is considered to be a sensitive period for the mother-infant relationship ${ }^{10}$.

Skin-to-skin contact positively influences the mother-infant relationship by promoting the initiation and duration of breastfeeding, enhancing attachment and bonding behaviours and positively influ- encing maternal-infant affectionate touch. This contact also helps protect against the harmful effects of maternal neonatal separation as well as supports optimal brain development and social-emotional intelligence for infants ${ }^{11-13}$.

The relationship between skin-to-skin contact and several of the beneficial outcomes are closely linked. This study had a specific focus on the outcomes of mother-infant bonding and touch. As can be seen in Figure I on page I2, skin-to-skin contact has a direct and indirect influence on the maternal-infant relationship. The bonding aspect of the mother-infant relationship refers to the affectionate and emotional tie from a caregiver to an infant ${ }^{14}$. Furthermore, skin-to-skin contact also has an influence on maternal-infant touch behaviours, specifically affectionate touch. This is defined as gentle touch that does not have a functional purpose but is rather used to express affection ${ }^{15}$.

Maternal-infant bonding and touch are central to an infant's social-emotional development ${ }^{16}$. In the early stages of infancy, social-emotional development can only be viewed in the context of relationship. Infants do not develop social-emotional skills in isolation but rather within a reciprocal relationship with their caregivers ${ }^{17}$. Social-emotional development is important because it lays the foundation for infants' cognitive and language development as well as adaptive life skills ${ }^{18}$.

Interventions that influence the mother-infant relationship and the development of social-emotional skills are of particular relevance for populations of vulnerable infants and/or mothers ${ }^{19,20}$

It has been documented that vulnerable infant populations, such as those living in socially adverse conditions as well as high risk infants or infants born with a disability, are more prone to having suboptimal mother-infant relationships and poor social-emotional development ${ }^{16,17,19}$

Furthermore, mothers living with a disability or limiting illness as well as mothers in minority groups (such as teenage mothers) may 


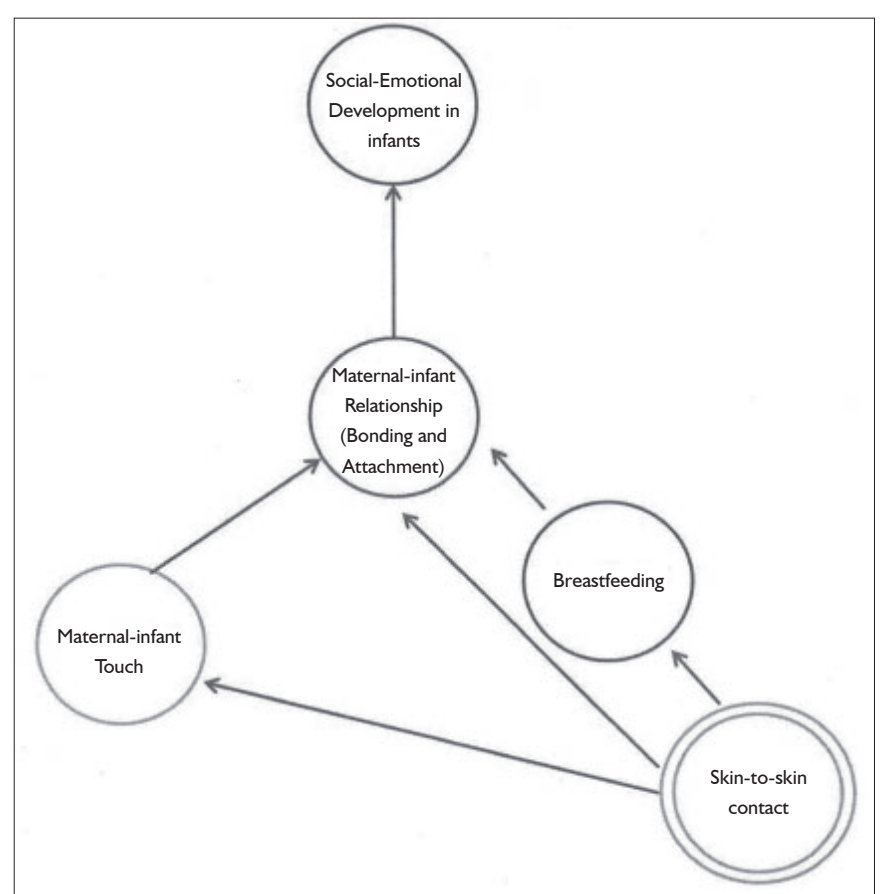

Figure I: Main concepts of the study and the relationships between them

also face multifaceted challenges that can impact on early parenting, bonding and attachment $\mathrm{t}^{20-22}$.

Occupational therapists are particularly well-suited to address these issues because of their understanding of illness, disability and social-economic contextual impact on participation in meaningful life roles and occupations ${ }^{23}$.

The above is especially relevant to the South African setting where there is a need to investigate interventions that can help address sub-optimal mother-infant relationships. This is emphasised by Cooper et al. ${ }^{19}$ who explain that populations of the developing world, like South Africa, are more prone to poverty and adverse mental health that negatively impact on this crucial relationship and therefore recommend further research into intervention.

There has also been a call for occupational therapists to become more involved in the pre- and postnatal care of low and high risk mothers and infants ${ }^{22,24}$. More specifically, South African occupational therapists have been urged to be more involved with supporting and promoting the co-occupation of breastfeeding, as members of the transdisciplinary team ${ }^{25}$. Skin-to-skin contact plays an integral role in the transitions of motherhood including the promotion of breastfeeding ${ }^{1,13,25}$. Furthermore, the American Occupational Therapy Association has specifically highlighted skin-to-skin contact as a priority research area as a touch-based intervention used to address social-emotional functioning ${ }^{26}$.

Several authors recommend studying low risk populations prior to studying vulnerable populations ${ }^{27,28}$. This study therefore set out to investigate the influence of early skin-to-skin contact on mother-infant bonding and touch with a population of low risk mothers and infants.

\section{LITERATURE REVIEW}

Skin-to-skin contact has a direct influence on the mother-infant relationship through the release of hormones which positively influence maternal mood and behaviour. This enhancement of feelings that mothers have for their infants help strengthen the bond between them ${ }^{27}$.

Bystrova et al. ${ }^{29}$ found that immediate skin-to-skin contact for 25 minutes to two hours after birth, together with early suckling, resulted in improved maternal sensitivity as well as better dyadic reciprocity and mutuality at one year after birth when compared to dyads that were separated after birth. There was however no statistical significance when the skin-to-skin dyads were compared to dyads that were dressed or swaddled and held after birth ${ }^{29}$.

Bigelow et al. ${ }^{30}$ conducted a randomised control study and found that the amount of skin-to-skin contact in the first 24 hours after birth was positively correlated with later maternal sensitivity at one year after birth.

Similarly, Bigelow and Power ${ }^{27}$ also studied the effects of extended skin-to-skin contact beyond the new-born period, specifically focussing on infants' social-emotional development in the context of mother-infant interaction. They found that infants that experienced extended skin-to-skin contact demonstrated changes in affect and increased attempts at interaction during the still-face task significantly earlier than infants that did not experience extended skin-to-skin contact. The study concluded that skin-to-skin contact facilitated infants' sensitivity and self-awareness of being active participants during social interactions with their mothers ${ }^{27}$.

Bigelow and Power ${ }^{27}$ suggest two reasons for why skin-to-skin contact may enhance bonding, attachment and infants' socialemotional development in the context of the mother-infant relationship. Firstly they state that skin-to-skin contact helps to promote the quiet alert state in the early postpartum period. This is an important state for taking in information from the outside world and thus promoting cognitive and social-emotional development. Secondly, skin-to-skin contact stimulates the release of oxytocin in mothers and infants. Oxytocin is a hormone released during and after childbirth. It stimulates sociability and trust as well as decreases fear and anxiety between individuals thus facilitating bonding and attachment ${ }^{27,31,32}$.

Skin-to-skin contact also indirectly influences the mother-infant relationship through breastfeeding and touch. There is a large body of evidence that supports the assertion that skin-to-skin contact positively influences breastfeeding ${ }^{7,33}$. This is of importance because breastfeeding is a key contributor to infants' health and survival ${ }^{34}$. Breastfeeding also acts as an enhancer of the mother-infant relationship. Similar to skin-to-skin contact, breastfeeding has a psychobiological influence on maternal behaviour ${ }^{35}$. It also has a positive influence on infants' development and alertness ${ }^{36}$. The effect that breastfeeding has on both mothers and infants contributes to its overall impact on the mother-infant relationship.

Similarly, touch is also considered an important contributor to the mother-infant relationship. A mother's touch is a central feature of a responsive daily caregiving routine that helps to nurture an infant's sense of trust. Positive maternal touch, especially affectionate touch, promotes infant's social and cognitive development and aids the connection between mothers and infants ${ }^{28}$. Jean and Stack ${ }^{37}$ identified that mothers touch their infants between 55 and $99 \%$ of the time during parent-infant face-to-face interaction. The frequency of this touch indicates its importance to maternal-infant interaction $^{38}$. There have however been no large scale crosssectional or longitudinal studies conducted on tactile interactions between adults and infants during face-to-face interactions thus no norms for tactile interactions exist ${ }^{39}$.

It has been suggested that skin-to-skin contact has a positive influence on maternal-infant tactile interactions. Anderson et al. ${ }^{40}$ report that skin-to-skin contact increases mothers desire to hold their infants. This is supported by the descriptive findings of Finigan and Davies ${ }^{41}$ who examined women's experience of skin-to-skin contact after birth with their infants. They found that mothers who experienced early skin-to-skin contact with their infants felt a strong desire to touch and stroke their infants and they did not want to let their infants go ${ }^{41}$.

Feldman et al. ${ }^{2}$ found that mothers who practiced skin-to-skin contact with their premature infants tended to touch them more than mothers who did not experience skin-to-skin contact. This finding is supported by another study that examined the influence of maternal-infant skin-to-skin contact on family interaction and touch with a population of preterm infants at three months corrected age. It was found that early skin-to-skin contact was positively correlated with less parental intrusiveness, higher parent-infant sensitivity and 
reciprocity, less negative emotion in infants and more parent-toinfant affectionate touch ${ }^{42}$.

A possible dose-response relationship is suggested in the systematic review by Anderson et al.' '. A dose-response refers to the change in effect caused by different levels of exposure ${ }^{33}$. It was concluded that the effects of skin-to-skin contact on positive maternal touch behaviours were more significant when compared to dyads that were separated after birth (no exposure) rather than dyads that were swaddled but still held after birth (some exposure)'.

\section{METHOD}

A quantitative correlational study design was used to examine whether correlations exist between the amount of skin-to-skin contact after birth and maternal-infant bonding and touch outcomes. Two skin-to-skin groups were compared. Dyads that experienced at least two hours of skin-to-skin contact directly after birth formed the high skin-to-skin group whereas dyads that did not experience skin-to-skin contact for two hours formed the low skin-to-skin group.

The study population consisted of mother-infant dyads within the private health care sector in Gauteng, South Africa. A convenience, purposive sampling method was used to recruit maternity facilities to take part in the study ${ }^{43}$. The private sector was deemed most appropriate as there were maternity facilities both with and without BFHI status that were geographically accessible to the researcher and whose policies allowed for research to take place. $\mathrm{BFHI}$ policy states that infants should be placed in immediate skinto-skin contact with their mothers directly after birth until the first breastfeed or for at least two hours after birth. Recruitment from hospitals with BFHI status would therefore help with obtaining dyads for the high skin-to-skin group. Hospitals without BFHI status did not have specific policies regarding early skin-to-skin contact thus the practice was very variable. Recruitment from non-BFHI hospitals assisted with obtaining dyads for both the high and low skin-to-skin groups, depending on the amount of skin-to-skin contact experienced. Three maternity facilities granted permission to be a part of the research. This included one facility with BFHI status and two without.

The researcher acquired a convenience sample by recruiting participants (mother-infant dyads) that met the inclusion criteria of the study ${ }^{43}$. Potential participants were approached and invited to participate in the study either prior to hospital admission (at antenatal classes) or during their post-natal hospital stay. This was done according to the specific requirements of the maternity facilities.

The inclusion and exclusion criteria requirements for selection of participants were as follows:

\section{Inclusion criteria}

* Primiparous and multiparous mothers who gave birth to healthy full term infants at private maternity facilities.

* Vaginal and caesarean section deliveries.

* Mothers who did not have to return to work for at least two months after giving birth and who intended to be their infant's main caregiver over this period.

\section{Exclusion criteria}

* Mothers and/or infants who required emergency medical treatment before or after birth or suffered from a significant illness in the first two months after birth

* Mothers who had given birth to multiple infants e.g. twins or triplets.

This sample size for this study was $4 \mathrm{I}$. A power calculation determined that the required sample size was at least 40 participants (20 participants per group) with a confidence interval of $+/-0.46$. The measurement tools used in the study included the contact and tactile questionnaires, Mother-to-infant Bonding Scale (MIBS) ${ }^{44}$ and coding of touch behaviours according to the Face-to-face interaction touch coding manual ${ }^{45}$ together with an additional definition of affectionate touch from the Micro-Coding Parent-Infant Interactions ${ }^{15}$.
The contact and tactile questionnaires were developed by the researcher. The contact questionnaire was developed in consultation with a skin-to-skin contact subject specialist. This questionnaire gathered information regarding mother-infant contact (including skin-to-skin contact) over the first 24 hours after birth. The tactile questionnaire gathered subjective information regarding current mother-infant touch behaviour in daily living, with a specific focus on affectionate touch. To ensure validity of these questionnaires, they were reviewed by the skin-to-skin contact subject specialist and two paediatric occupational therapists. The content and layout of the questionnaires were amended following recommendations from the specialist and therapists. Furthermore, a pilot study was completed with a small sample of the population (four mothers) to evaluate the comprehensiveness and efficiency of the questionnaires. The alpha score for the finalized questionnaires was 0.399 . The low score may be due to the small sample size as well as the test length being short ${ }^{46}$.

The MIBS has been used in several previous studies examining mother-infant bonding. It has an acceptable internal consistency of $\alpha=0.71^{47}$. The Face-to-face interaction touch coding manual ${ }^{45}$ was used to examine the type and duration of mother-infant touch including active, passive and no touch categories. Affectionate touch was also examined using an additional definition from the Micro-Coding Parent-Infant Interactions ${ }^{15}$. The Face-to-face interaction touch coding manual and the Micro-Coding Parent-Infant Interaction tools have previously been identified as having an interrater reliability scores of $84.7 \%$ and $93 \%$ respectively ${ }^{38,42}$.

The first point of data collection was within one week after birth but not earlier than 24 hours after birth to ensure adequate recovery time. All participating mothers were requested to complete the contact questionnaire and the MIBS at this first point of contact. Based on the information obtained in the contact questionnaire, participants were placed in either the high or low skin-to-skin groups.

A second point of contact took place between six and eight weeks after birth. The participants were asked to complete the tactile questionnaire and repeat the MIBS. Participating dyads were then videotaped during face-to-face interaction. These videotapes were later analysed and coded.

The study data was captured onto Excel spreadsheets before being entered into Statistica I3.0 for further quantitative analysis. Descriptive and non-parametric statistics were used to analyse the study data. Pearson's chi-square test was used to analyse nominal data. The Mann Whitney $U$ test was used to analyse ordinal and ratio data. Furthermore, clinical difference was tested using Cohen's $d$ effect size calculation with ratio data and $r$ effect size calculation with ordinal data.

Data sets were collected over a period of 10 months until there were at least 20 participants in both the high and low skin-to-skin groups and to cover the six to eight week follow-up period.

All participants gave written informed consent prior to commencement in the study. Ethical approval for this study was obtained from the University of Witwatersrand Human Research Ethics Committee (Clearance certificate number No. MI40867).

\section{RESULTS}

The study sample was made up of a total of 41 mother-infant dyads. Twenty one dyads formed the low skin-to-skin group and 20 formed the high skin-to-skin group.

All $4 \mathrm{I}$ dyads completed the first half of the study. Thirty-seven of the initial 4 I dyads completed the second half of the study. Three dyads from the low skin-to-skin group and one from the high skinto-skin group did not complete the second half of the study. Of the 37 dyads that did complete the second half of the study, videos could not be taken for five dyads. This was due to the infants not being in an appropriate state of arousal to take part in face-to-face interaction during the researcher's follow-up visit. 
The age range of participating mothers was 22 to $4 \mathrm{I}$ years with the average age being 30 years. The majority of the mothers $(73 \%)$ were primiparous and the minority $(27 \%)$ was multiparous. The high and low skin-to-skin groups were comparable in terms of age $(p=0.79)$ and parity $(p=0.06)$.

In the total infant study sample, twenty four (59\%) were female and $17(41 \%)$ were male. Nineteen $(46 \%)$ were born via caesarean section and $22(54 \%)$ were born via vaginal delivery. The high and low skin-to-skin groups were comparable in terms of infant gender $(p=0.4 \mathrm{I})$, type of delivery $(p=0.16)$ and birth weight $(p=0.17)$. There were however significantly more $(p=0.02)$ infants in the high skin-to-skin group that were recruited from the maternity facility with $\mathrm{BFHI}$ status in comparison to the low skin-to-skin group.

Of the total sample, 20 (48\%) maternal-infant dyads experienced immediate skin-to-skin contact for at least two hours after birth, as indicated by the contact questionnaire, and thus formed the high skin-to-skin group. Twenty one (52\%) maternal-infant dyads did not experience immediate skin-to-skin or they did not experience skin-to-skin contact for a minimum of two hours and thus formed the low skin-to-skin group.

Within the low skin-to-skin group, eight dyads (38\%) did not experience immediate skin-to-skin contact and 13 dyads (62\%) did. Of the 13 dyads that did experience skin-to-skin contact, three dyads did so for less than 10 minutes, four dyads for 10 to 30 minutes and six dyads for 30 to 60 minutes.

Highly statistically significant correlations were identified in favour of the high skin-to-skin group for length of time in skin-toskin contact immediately after birth $(p=0.000)$ and skin-to-skin contact over the first 24 hours after birth $(p=0.009)$.

\section{Results of the Maternal-Infant Bonding Scale (MIBS)}

Mothers completed the MIBS twice during the study. The first completion was within one week after birth (referred to as MIBS I) and then again at six to eight weeks after birth (referred to as MIBS 2). All 4 I mothers completed the MIBS I whereas only 37 mothers completed the MIBS 2.

\section{MIBS I}

The high and low skin-to-skin group mothers' reporting of bonding with their infants was very similar for the MIBS I. Neither a statistically significant difference $(p=0.64)$ nor an effect size $(d=$ -0.02 ) was identified between the two groups.

\section{MIBS 2}

Thirty seven mothers completed the MIBS 2; 19 from the high skin-toskin group and 18 from the low skin-to-skin group. The mean score of the high skin-to-skin group was $0.65(\mathrm{SD}=1.09)$ and the mean score from the low skin-to-skin group was I.00 $(S D=1.48)$. Lower scores on the scale indicate fewer bonding disturbances. The majority $(n=$ 12) of mothers from the high skin-to-skin group (63\%) scored 0 on the MIBS 2, whereas only 8 (44\%) from the low skin-to-skin group scored the same. These findings were supported by a small effect size $(d=-0.27)$. This indicated that mothers from the low skin-to-skin group reported more disturbances in the mother-infant bond than those in the high skin-to-skin group. There was however no statistically significant difference $(p=0.4 \mathrm{I})$ found between the two groups.

\section{Results of mother-infant touch}

The study examined both subjective reports of mothers' affectionate touch behaviours towards their infants as well as looked at an objective analysis of mother-infant touch during video-taped episodes of face-to-face interaction.

\section{The tactile questionnaire}

Thirty seven participants completed the tactile questionnaire, 19 from the high skin-to-skin group and 18 from the low skin-to-skin group. No statistical significance was found between the two groups in any of the categories but some clinical difference was identified. This included a small effect size for affectionate touch during feeding $(r=0.27)$ in favour of the high skin-to-skin group.

\section{Mother-infant touch during face-to-face interaction}

In total 32 dyads took part in the interaction task, 16 from the high skin-to-skin group and 16 from the low skin-to-skin group. Overall the high skin-to-skin group spent more time touching their infants during face-to-face interaction than the low skin-to-skin group. This can be seen in the higher median and mean scores for the passive, active and affectionate categories of touch (see Table I below). This was also supported by the finding that the low skin-to-skin group had a higher mean score in the no touch category than the high skin-to-skin group. The high skin-to-skin group spent $81 \%$ of the time using some form of touch with their infants, whereas the low skin-to-skin group did the same for $71 \%$ of the time during the face-to-face interaction. Despite this difference, no statistical significance was identified between the two groups in any of the categories. Small effect sizes were however found for the passive $(d=0.22)$ and affectionate $(d=0.24)$ categories of touch and a medium effect size for the active $(d=0.59)$ category of touch, all in favour of the high skin-to-skin group.

\section{DISCUSSION}

No correlation was found between a longer duration of early skinto-skin contact and bonding outcomes within one week postpartum.

Table I: Results of tactile interactions: Time spent engaging in passive, active, no touch and affectionate touch during face-to-face interaction $(n=32)$

\begin{tabular}{|c|c|c|c|c|c|c|c|}
\hline \multirow{2}{*}{$\begin{array}{l}\text { Variable } \\
\text { (Time) }\end{array}$} & $\begin{array}{l}\text { Experimental } \\
\text { Group }(n=16)\end{array}$ & $\begin{array}{c}\text { Control Group } \\
(n=16)\end{array}$ & \multirow{2}{*}{$\begin{array}{l}\text { Change in } \\
\text { Median }\end{array}$} & \multirow{2}{*}{ p value } & $\begin{array}{l}\text { Experimental } \\
\text { Group }(n=16)\end{array}$ & $\begin{array}{c}\text { Control Group } \\
(n=16)\end{array}$ & \multirow{2}{*}{$\begin{array}{l}\text { Effect Size } \\
\text { Cohen's d }\end{array}$} \\
\hline & \multicolumn{2}{|c|}{$\begin{array}{c}\text { Median } \\
\text { (Lower and Upper quartile) }\end{array}$} & & & \multicolumn{2}{|c|}{ Mean (SD) } & \\
\hline Passive & $\begin{array}{c}19.02 \\
(5.95-33.20) \\
\end{array}$ & $\begin{array}{c}14.35 \\
(03.04-27.92) \\
\end{array}$ & 04.67 & 0.58 & $19.37(14.60)$ & $16.14(14.34)$ & $0.22^{\circ}$ \\
\hline Active & $\begin{array}{c}41.31 \\
(35.32-48.38)\end{array}$ & $\begin{array}{c}31.83 \\
(12.67-48.00)\end{array}$ & 09.48 & 0.17 & $40.56(12.20)$ & 30.91 (19.66) & $0.59{ }^{\circ}$ \\
\hline No Touch & $\begin{array}{c}10.50 \\
(2.42-17.60) \\
\end{array}$ & $\begin{array}{c}09.80 \\
(01.83-18.65) \\
\end{array}$ & 00.70 & 0.98 & $11.47(10.62)$ & 14.01 (15.85) & 0.19 \\
\hline Affectionate & $\begin{array}{c}15.30 \\
(9.36-21.75)\end{array}$ & $\begin{array}{c}11.01 \\
(07.95-17.97)\end{array}$ & 04.29 & 0.44 & $17.20(1 \mid .52)$ & |4.48 (I I.56) & $0.24^{\circ}$ \\
\hline \multicolumn{8}{|c|}{$\begin{array}{l}p \leq 0.05 \text { Statistical significance* } \\
p \leq 0.0 \text { I High statistical significance } * * \\
d \geq 0.8 \text { Large effect size } \cdots \\
d \geq 0.5 \text { Medium effect size } \cdot . \\
d \geq 0.2 \text { Small effect size }\end{array}$} \\
\hline
\end{tabular}


A positive correlation was identified between a longer duration of early skin-to-skin contact and outcomes of bonding and selfreported affectionate touch during feeding at six to eight weeks postpartum. This was substantiated by an increase in touch during objectively assessed face-to-face interaction.

\section{Maternal-infant bonding}

The results of MIBS I are in contrast with existing research. The current study found no significant difference in reports of bonding between the high and low skin-to-skin groups whereas previous research has found that early skin-to-skin contact resulted in improved mother-infant relations ${ }^{13,29,33,48,49}$. More specifically, Bystrova et al. ${ }^{29}$ found that skin-to-skin contact for 15 to 60 minutes had a positive influence on mother-infant interaction and maternal affectionate behaviour on day four postpartum. This is supported by the findings of multiple studies conducted in the 1970-1980s that compared the behaviours of mothers that had experienced brief periods of skin-to-skin contact (as little as 15 minutes) with their infants immediately after birth versus mothers that only had contact with their infants every four hours and were otherwise kept separate in the nursery. At the end of the postpartum stay, mothers that had experienced only brief skin-to-skin contact displayed more confidence when handling and caring for the infants when compared to the mother-infant dyads that had been separated from one another ${ }^{1,33}$. In the present study, $62 \%$ of the low skin-to-skin group experienced some skin-to-skin contact, ranging from I to 60 minutes, immediately after birth. It is thus possible that even the brief time spent in skin-to-skin contact could have influenced the mother-infant bonding outcomes of the low skin-to-skin group.

A small effect size was identified at the six to eight week follow-up on the influence of at least two hours of skin-to-skin contact after birth on bonding in favour of the high skin-to-skin group. A dose-response of the longer duration of initial skin-to-skin contact between the two groups may have influenced this longer term outcome. This is supported by the findings of Bystrova et al. ${ }^{29}$ who found that early skin-to-skin contact positively affected maternal sensitivity, dyadic mutuality and reciprocity at one year postpartum. Bramson et al. ${ }^{50}$ also identified a dose-response effect of skin-to-skin contact. They specifically highlighted the importance of early contact as well as contact as often as possible, and for as long as possible for at least the duration of the postpartum stay. The mothers in the high skin-to-skin group reported having spent not only longer in immediate skin-to-skin contact after birth but also having a longer duration of skin-to-skin contact in the first 24 hours after birth. It is therefore possible that together this longer duration of skin-to-skin contact during the postpartum stay had a dose-response effect on the later report of mother-infant bonding, in which the high skin-to-skin group reported fewer disturbances than the low skin-to-skin group.

To help us understand the underlying mechanisms behind the influence of skin-to-skin contact on bonding, Bigelow and Power ${ }^{27}$ report that on a physiological level skin-to-skin contact acts as an oxytocin releasing agent in mothers. Early suckling and infant touch of the breast also releases oxytocin in mothers ${ }^{51}$. Oxytocin promotes maternal affiliative behaviours, positive maternal mood as well as positive maternal feelings towards their infants thus enhancing bonding $2,27,52$.

\section{Mother-infant touch}

This study identified a clinical difference in the self-reported motherinfant affectionate touch during feeding, in favour of the high skinto-skin group. Furthermore, the objective analysis of mother-infant touch during face-to-face interaction found that mothers from the high skin-to-skin group spent more time touching their infants than mothers from the low skin-to-skin group.

The high skin-to-skin group spent $81 \%$ of the time using some form of touch with their infants, whereas the low skin-to-skin group did the same for $71 \%$ of the time during face-to-face interaction. These findings, for both groups, are in line with previous literature regarding the percentage of time mothers spend touching their infants ${ }^{37}$.

The difference in the quantity of touch between the high and low skin-to-skin groups are also similar to the study by Feldman et al. ${ }^{2}$ who found that mothers that had experienced skin-to-skin contact with their infants tended to touch them more than nonskin-to-skin mothers.

The findings of the current study are also in line with previous literature that states that mothers who touch their infants more also tend to use all forms of touch more frequently than mothers that provide less touch to their infants ${ }^{53}$. This is true for the current study whereby the high skin-to-skin group had a higher percentage of total touch as well as higher frequency of touch in all categories (passive, active and affectionate).

In addition to the quantity of touch, the type of touch provided has also been highlighted as being of importance ${ }^{54}$. Weiss et al. ${ }^{54}$ specifically delineate touch with regards to the degree to which it is tender and affectionate versus the degree to which it is rejecting or abusive. The high skin-to-skin group used more affectionate touch during enface interaction than the low skin-to-skin group. Neither of the groups were observed using any form of negative or rejecting touch during the interaction episodes. These findings are similar to early research which states that early skin-to-skin contact increased later maternal affectionate touch behaviours ${ }^{55-58}$. In a more recent study, a significant positive effect of skin-to-skin contact on affectionate touch was also identified ${ }^{42}$.

A possible underlying reason for this association can again be attributed to the effects of oxytocin. Bigelow and Power ${ }^{27}$ report that oxytocin, released during skin-to-skin contact and breastfeeding contributes to maternal affiliative behaviours such as touch, gaze and positive vocal and facial expression. This cycle then continues as more oxytocin is produced through maternal-infant touch and sustained physical contact ${ }^{27}$.

Although the findings of the current study are in agreement with previous literature, there were only small effect sizes whereas previous studies identified greater significance'. This may be due to the dose-response of skin-to-skin contact and the comparison with other forms of contact versus mother-infant separation $1,9,33,50$. As previously discussed, $62 \%$ of the low skin-to-skin group experienced some skin-to-skin contact with their infants after birth. It is possible that the effects of skin-to-skin contact on later positive touch behaviours would have been more exaggerated if the high skin-to-skin group were compared to a low skin-to-skin group that had not experienced any skin-to-skin contact, or even more significant, if they had been separated from their infants after birth. Previous studies have found that the effects of skin-to-skin contact were less significant when compared to a control group who swaddled their infants after birth versus a control group that were separated from their infants after birth'. This is supported by Feldman et al. ${ }^{42}$ who found that early separation specifically decreased later maternal-infant touch and proximity.

In contrast to the assumption that greater quantities of touch are better, some studies have noted that too much touch can in fact have a negative impact on attachment. Excessively stimulating or intrusive caregiving approaches not in line with the infant's needs are associated with insecure attachment whereas a more moderate amount of stimulation is related to a greater security of attachment ${ }^{54,59}$

On the other hand, Feldman et $a . .^{42}$ have said that a decrease in positive maternal touch is related to maternal depression and intrusiveness. This is supported by the finding that reduced parental affectionate touch is directly related to family intrusiveness and that family cohesiveness could be predicted by the amount of affectionate touch ${ }^{42}$.

\section{Implications of the research}

These findings are important for the practice of occupational therapy because it furthers our understanding of how to better support the vital mother-infant relationship. This primary relationship forms 
the foundation for the development of infants' social-emotional skills $^{16}$. Thus by supporting the mother-infant relationship we are in turn supporting infants' social-emotional development.

Occupational therapists can use this knowledge, in conjunction with previous research, to continue to support the use of skin-to-skin contact with high risk and/or premature infants. This is of particular relevance in South African because of the high rate of premature birth ${ }^{60}$.

Occupational therapy intervention with other vulnerable mother and/or infant populations as well as with low risk populations is considered a non-traditional field of specialisation ${ }^{22}$. This is despite a call more than a decade ago for occupational therapists to become more involved in pre- and postnatal care ${ }^{24}$. This call is reiterated in Slootjies et al. ${ }^{22}$ paper on the important contributions occupational therapists can have on the transitions in motherhood. Occupational therapists are well suited to enhance wellbeing and occupational performance as well as to help achieve improved health outcomes for mother-infant dyads within the transdisciplinary team ${ }^{22,23}$. The use of skin-to-skin contact can specifically be used with high and low risk dyads to enhance the mother-infant relationship

Furthermore, skin-to-skin contact is also a precursor to breastfeeding which, as established, is a very important means of reducing infant mortality and morbidity. This has specifically been raised as a concern in South Africa ${ }^{8}$. Occupational therapists have been called to action to assist with supporting and promoting the co-occupation of breastfeeding as members of the transdisciplinary team. Part of this approach should include the use of early skin-to-skin contact ${ }^{25}$.

\section{Limitations of the research}

This study lacked methodological soundness. This could have been improved by three means. Firstly, the use of a randomized control trial (including randomization of maternity facilities and participants into intervention groups) would be a more rigorous means of detecting a cause-effect relationship. This would also help to rule out confounding variables influencing the results. Secondly, all methods of data collection should be standardized and subjective information from participating mothers should be validated objectively. Thirdly, to avoid any bias, a blind researcher should be used to complete the tactile interaction coding.

\section{CONCLUSION}

This study set out to examine the influence of early skin-to-skin contact for at least two hours after birth on mother-infant bonding, touch in daily routine and tactile interactions with a population of low risk mothers and infants in South Africa.

This study found that early skin-to-skin contact had a positive influence on mother-infant bonding, affectionate touch in daily routine and tactile interactions between mothers and infants. The results were however variable in significance and clinical effect. Further more stringent research is required to confirm these findings.

These findings are an important contribution to occupational therapy literature and support the use of skin-to-skin contact as a means of intervention with low and high risk populations. Occupational therapists are called to become more involved with pre- and postnatal care of mothers and infants as well as to support breastfeeding as a health-promoting co-occupation. Early skin-to-skin contact forms an integral part in these transitions of motherhood.

\section{REFERENCES}

1. Anderson GC, Moore E, Hepworth J, Bergman N. Early skin-to-skin contact for mothers and their healthy new born infants. Cochrane Database of Systematic Reviews. 2007; 3(3): I.

https://doi.org/0.1002/14651858.CD003519.pub2.

2. Feldman R, Eidelman Al, Sirota L, Weller A. Comparison of skinto-skin (kangaroo) and traditional care: Parenting outcomes and preterm infant development. Pediatrics. 2002; IIO(I): 16-26.

3. Blomqvist YT, Nyqvist KH. Swedish mothers' experience of continuous kangaroo mother care. Journal of Clinical Nursing. 20 I0; 20: 1472-80.

https://doi.org//0.1 I I I/j.1365-2702.2010.03369.x.
4. Ludington-Hoe SM. Kangaroo care as a neonatal therapy. New born and Infant Nursing Reviews. 20 I3; 13(2): 73-5. Article in Newborn and Infant Nursing Reviews. 2013; I3(2): 73-75.

https://doi.org//0.1053/j.nainr.2013.03.004.

5. Venancio Sl, de Almeida $\mathrm{H}$. Kangaroo mother care: Scientific evidences and impact on breastfeeding. Jornal de Pediatria. 2004; 80(5): 173-80.

6. World Health Organization. Division of Child Health and Development. Evidence for the ten steps to successful breastfeeding. Geneva: World Health Organization; 1998. Downloaded from: http://www. who.int//iris/handle/I0665/64877. Retrieved on 19 March 2016.

7. World Health Organization. Baby-friendly hospital initiative: Revised, updated and expanded for integrated care. Geneva: World Health Organization and UNICEF; 2009. Downloaded from:

http://whqlibdoc.who.int/publications/2009/978924I59498I_eng. pdf. Retrieved on I5 June 2015.

8. National Department of Health. The Tshwane declaration of support for breastfeeding in South Africa. The South African Journal of Clinical Nutrition. 20I I; 24(4): 2 I4.

9. Moore E, Anderson GC. Randomized controlled trial of very early mother-infant skin-to-skin contact and breastfeeding status. Journal of Midwifery and Women's Health. 2007; 52(2): I I6-25. https://doi.org/10.1016/j.mwh.2006.12.002.

10. Bergman NJ, Bergman J. Whose choice? Advocating birthing practices according to baby's biological needs. The Journal of Perinatal Education. 2013; 22(I): 8-13. https://doi.org/I0.1891//058-1243.22.1.8.

II. Henry S, Richard-Yris MA, Tordjman S, Hausberger M. Neonatal handling affects durably bonding and social development. PloS ONE. 2009; 4(4): e5216. https://doi.org//0.137//journal.pone.0005216.

12. Bergman NJ. "Skin-to-skin contact is key to perinatal neuroscience." What is skin-to-skin contact. 20I3. Available at:

http://www.skintoskincontact.com/ssc-neuroscience.aspx. (Accessed: 20 April 2016).

13. Phillips R. The sacred hour: Uninterrupted skin-to-skin contact immediately after birth. New born and Infant Nursing Reviews. 20 I3; 13(2): 67-72. https://doi.org/10.1053/j.nainr.2013.04.00I.

14. Kennell J, McGrath S. Starting the process of mother-infant bonding. Acta Paediatrica. 2005; 94(6): 775-8. Doi: | 0.1080/080352505।0035634.

I5. Feldman R. Micro-coding parent-infant interactions. Bar-llan, Israel: Bar-Ilan University, 2004

16. Case-Smith J. Systematic review of interventions to promote socialemotional development in young children with or at risk for disability. The American Journal of Occupational Therapy. 20 I 3; 67(4): 395-404. http://doi.org//0.50|4/ajot.2013.0047/3.

17. Malekpour M. Effects of attachment on early and later development. The British Journal of Developmental Disabilities. 2007; 53(2): 8I-95.

18. Greenspan S, Wieder S, Simons R. The child with special needs: Encouraging intellectual and emotional growth. Reading: MA Addison-Wesley, 1998.

19. Cooper PJ, Tomlinson M, Swartz L, Landman M, Molteno C, Stein A, McPherson K, Murray L. Improving quality of mother-infant relationships and infant attachment in socioeconomically deprived community in South Africa: Randomised controlled trial. British Medical Journal. 2009; 338(b974): I-8. https://doi.org// 0.1 I36/bmj.b974.

20. Meintjes I, Field S, Sanders L, van Heyningen T, Honikman S. Improving child outcomes through maternal mental health interventions. Journal of Child and Adolescent Mental Health. 2010; 22(2): 73-82. https://doi.org//0.2989/I 7280583.20I0.528576.

21. Redshaw M, Malouf R, Gao H, Gray R. Women with disability: The experience of maternity care during pregnancy, labour and birth and the postnatal period. BMC Pregnancy and Childbirth. 20I3; I3(I): 174.

22. Slootjes H, McKinstry C, Kenny A. Maternal role transition: Why new mothers need occupational therapists. Australian Occupational Therapy Journal. 2016; 63(2): 130-3. https://doi.org/I0.1 I I I/I440-1630.I 2225.

23. The American Occupational Therapy Association. Occupational therapy practice framework: Domain and process. American Journal of Occupational Therapy. 20I4; 68(SI): SI-S48. 
24. Esdaile S, Olson J. Mothering occupations: Challenge, agency, and participation. Philadelphia: F.A. Davis Company, 2004.

25. Visser M, Nel M, la Cock T, Labuschagne N, Lindeque W, Malan A, Viljoen C. Breastfeeding among mothers in the public health sector: The role of the occupational therapist. South African Journal of Occupational Therapy. 2016; 46(2): 65-72. http://dx.doi.org//0.17/59/2310-3833/2016/v46n2all.

26. The American Occupational Therapy Association. Research opportunities in the area of early childhood: Birth through 5 years. American Journal of Occupational Therapy. 20 I4; 68(3): 367-70.

27. Bigelow $A E$, Power $M$. The effect of mother-infant skin-to-skin contact on infants' response to the still face task from new born to three months of age. Infant Behavior and Development. 2012; 35(2): 240-5I. https://doi.org/10.1016/j.infbeh.201।.12.008.

28. O'Brien M, Lynch $\mathrm{H}$. Exploring the role of touch in the first year of life: Mothers' perspectives of tactile interactions with their infants. The British Journal of Occupational Therapy. https://doi.org/I0.4276/0308022 I IXI 2996065859247.

29. Bystrova K, Ivanova V, Edhborg M, Matthiesen A-S, Ransjö-Arvidson A-B, Mukhamedrakhimov R, Uvnäs-Moberg K, Widström AM. Early contact versus separation: Effects on mother-infant interaction one year later. Birth. 2009; 36(2): 97-109. https://doi.org/I 0.1 I I I/j. I523-536X.2009.00307.x.

30. Bigelow AE, Littlejohn M, Bergman NJ, McDonald C. The relation between early mother-infant skin-to-skin contact and later maternal sensitivity in South African mothers of low birth weight infants. Infant Mental Health Journal. 2010; 31 (3): 358-77. https://doi.org/10.1002/imhj.20260.

31. Carfoot S, Williamson P, Dickson R. A randomised controlled trial in the North of England examining the effects of skin-to-skin care on breast feeding. Midwifery. 2005; 2I (I), 7I-79.

32. Henderson A. Understanding the breast crawl implications for nursing practice. Nursing for Women's Health. 20I I; 15(4): 296-307. https://doi.org/I0.IIII/j. I75I-486X.20I I.01650.x.

33. Moore E, Anderson GC, Bergman NJ, Doswell T. Early skin-to-skin contact for mothers and their healthy new born infants (review). Cochrane Database of Systematic Reviews 20I 2; 5(3): https://doi.org/I0.1002/I465I858.CD0035I9.

34. Mason F, Rawe K, Wright S. Superfood for babies: How overcoming barriers to breastfeeding will save children's lives. London: Save the Children; 2013. Downloaded from:

https://www.google.co.za/url?sa $=$ t\& $\& \mathrm{rct}=\mathrm{j} \& \mathrm{q}=\&$ esrc $=\mathrm{s} \&$ source $=$ web\&cd $=5 \& \mathrm{cad}=$ rja\&uact $=8 \&$ ved $=0$ ahUKEwi $v 8 X W s f b O A h W$ FKMAKHTIpCS4QFghFMAQ\&url=https://www.savethechildren. org.uk/sites/default/files/images/Superfood for Babies UK version. pdf\&usg=AFQjCNFvINW-BOpN5Y4exno. Retrieved on II 5 April 2016.

35. Kim P, Feldman R, Mayes LC, Eicher V, Thompson N, Leckman JF, Swain JE. Breastfeeding, brain activation to own infant cry, and maternal sensitivity. Journal of Child Psychology and Psychiatry. 20II; 52(8): 907-15. https://doi.org/I0.1 I I I/j. I469-76/0.201 I.02406x.

36. Feldman R, Eidelman Al. Direct and indirect effects of breast milk on the neurobehavioral and cognitive development of premature infants. Developmental Psychobiology. 2003; 43(2): 109-19. https://doi.org/10.1002/dev.10126.

37. Jean $A D$, Stack DM. Full-term and very-low-birth-weight preterm infants' self-regulating behaviours during a still-face interaction: Influences of maternal touch. Infant Behavior and Development. 20I2; 35(4): 779-9I. https://doi.org/10.1016/j.infbeh.2012.07.023.

38. Koester LS, Brooks L, Traci M. Tactile contact by deaf and hearing mothers during face-to-face interactions with their infants. Journal of Deaf Studies and Deaf Education. 2000; 5(2):127-39. https://doi.org/10.1093/deafed/5.2.127.

39. Muir DW. Adult communications with infants through touch: The forgotten sense. Human Development. 2002; 45(2):95-9. https://doi.org/10.1 I59/000048/55

40. Anderson GC, Chiu S, Dombrowski M, Swinth J, Albert J, Wada $\mathrm{N}$. Mother-new born contact in a randomized trial of kangaroo (skin-to-skin) care. Journal of Obstetric, Gynecologic, and Neonatal Nursing. 2003; 32(5): 604-II.

https://doi.org//0.1 I 77/08842175032566/6.
4I. Finigan V, Davies S. “I just wanted to love, hold him forever": Women's lived experience of skin-to-skin contact with their baby immediately after birth. Evidence-Based Midwifery. 2004; 2(2): 59-66.

42. Feldman R, Weller A, Sirota L, Eidelman Al. Testing a family intervention hypothesis: The contribution of mother-infant skin-to-skin contact (kangaroo care) to family interaction, proximity, and touch. Journal of Family Psychology. 2003; I7(I): 94-I07.

43. Kielhofner G. Research in occupational therapy: Methods on inquiry for enhancing practice. Philadelphia: F.A. Davis Company, 2006.

44. Taylor A, Atkins R, Kumar R, Adams D, Glover V. A new motherto-infant bonding scale: Links with early maternal mood. Archives of Women's Mental Health. 2005; 8(I): 45-5I. https://doi.org/10.1007/s00737-005-0074-z.

45. Koester LS. Face-to-face interaction touch coding manual. Missoula, Montana: The University of Montana, 1995.

46. Heale R, Twycross A. Validity and reliability in quantitative studies. Evidence Based Nursing. 2015; 18(3): 66-7.

47. Perrelli JGA, Zambaldi CF, Cantilino A, Sougey EB. Mother-child bonding assessment tools. Revista Paulista De Pediatria. 20I4; 32(3): 257-65.

48. Widström AM, Wahlberg V, Matthiesen AS, Eneroth P, UvnäsMoberg K, Werner S, Winberg J. Short-term effects of early suckling and touch of the nipple on maternal behaviour. Early Human Development. 1990; 21 (3): 153-63.

49. Winberg J. Mother and new born baby: Mutual regulation of physiology and behaviour - A selective review. Developmental Psychobiology. 2005; 47(3): 217-29.

https://doi.org/I0.1002/dev.20094.

50. Bramson L, Lee JW, Moore E, Montgomery S, Neish C, Bahjri K, Melcher CL. Effect of early skin-to-skin mother-infant contact during the first 3 hours following birth on exclusive breastfeeding during the maternity hospital stay. Journal of Human Lactation. 20 I0; 26(2): I30-7. https://doi.org// 0.I I 77/0890334409355779.

51. Matthiesen A, Ransjö-Arvidson A-B, Nissen E, Uvnäs-Moberg K. Postpartum maternal oxytocin release by new borns: Effects of infant hand massage and sucking. Birth. 200I; 28(I): I3-9.

52. Insel TR, Young $L$ J. The neurobiology of attachment. Nature Reviews Neuroscience. 200I; 2(2): 129-36. https://doi.org//0.1038/35053579.

53. Ferber SG, Feldman R, Makhoul IR. The development of maternal touch across the first year of life. Early human development. 2008; 84(6): 363-70.

https://dx.doi.org/10.1016/j.earlhumdev.2007.09.019.

54. Weiss SJ, Wilson P, Hertenstein MJ, Campos R. The tactile context of a mother's caregiving: Implications for attachment of low birth weight infants. Infant Behavior and Development. 2000; 23(I): 9I-III. http://doi.org/10.1016/S0163-6383(00)00030-8.

55. De Chateau P, Wiberg B. Long-term effect on mother-infant behaviour of extra contact during the first hour post partum II: A follow-up at three months. Acta Paediatrica Scandinavica. I 977; 66 (I): I45-5I.

56. Hales D, Lozoff B, Sosa R, Kennell J. Defining the limits of the maternal sensitive period. Developmental Medicine and Child Neurology. 1977; 19(4): 454-6I.

57. Curry M. Contact during the first hour with the wrapped or naked new born: Effect on maternal attachment behaviours at 36 hours and three months. Birth. 1979; 6(4): 227-35.

58. Anisfeld E, Lipper E. Early contact, social support and mother-infant bonding. Pediatrics. 1983; 72(1): 79-83.

59. Lewis M, Feiring C. Infant, mother and mother-infant interaction behaviour and subsequent attachment. Child Development. 1989; 60(I): 83I-7.

60. Lubbe W. What is prematurity? Little Steps; 2016. Downloaded from: http://www.littlesteps.co.za/index.php?option $=$ com_content\&vie $\mathrm{w}=$ article\&id $=93$ \&ltemid $=5 \mathrm{I}$. Retrieved on 23 August $20 \mathrm{I} 6$. 